\title{
SEMASIOLOGIS DALAM BAHASA TORAJA
}

\author{
Resnita Dewi*, Paulina Pulung², Abdul Muttalib ${ }^{3}$
}

\begin{abstract}
This study aims to describe semasiologi in Toraja. This research is a type of comparative qualitative research. The data in this study were Toraja based on two hundred Gloss Swadesh collected from informants in five research locations, namely Rembon, Makale, Salubarani, Sa'dan, and Baruppu. Data was collected using interview techniques and noted. The results of the study show that semasiologically found in Toraja. Semasiologi refers to the meaning of two forms of the same language but has different concepts or meanings. Semasiology in the Toraja language can be found in the words sia, sola, tambuk, penaa, ula ', baine, muane, and five.
\end{abstract}

Keywords: Semasiologis, Toraja Language

\section{PENDAHULUAN}

Bahasa sebagai alat komunikasi atau interaksi memungkinkan setiap orang untuk dapat merasa bahwa dirinya terikat dengan kelompok sosial yang dimasukinya, serta dapat melakukan semua kegiatan sosial yang terjadi pada komunitas tempat dia berada. Bahasa Toraja sebagai salah satu satu bahasa juga mengemban tugas tersebut. Bahasa Toraja digunakan oleh masyarakat Toraja untuk berkomunikasi, baik dalam situasi formal maupun nonformal, baik secara lisan maupun tertulis. Penggunaan bahasa Toraja dalam situasi formal, dapat dilihat pada upacara Rambu Solo'. Adapun penggunaan bahasa Toraja dalam situasi nonformal dapat dilihat dalam komunikasi sehari-hari misalnya saat berada di rumah, di pasar, dan dalam situasi nonformal lainnya.

*) Prodi. Bahasa Indonesia, Universitas Kristen Indonesia Toraja

E-mail: resnita@ukitoraja.ac.id 
Dalam penggunaan bahasa Toraja secara khusus, dan semua bahasa pada umumnya, kita sering menemukan adanya dua bentuk bahasa yang sama namun memiliki konsep atau makna yang berbeda. Kasus atau gejala demikian disebut semasiologis. Semasiologis adalah pemberian nama yang sama untuk beberapa konsep yang berbeda (Guiraud, 1970: 17-18). Contohnya kata aceh [ackh] mengandung makna nama suku bangsa, nama daerah, dan nama kebudayaan, namun disisi lain, kata aceh [acch] juga merupakan nama sejenis rambutan.

Selama ini, semasiologis banyak dikaji berkaitan dengan dialektologi. Dialektologi merupakan cabang linguistik yang mempelajari variasi bahasa (Nadra dan Reniwati, 2009:4; Chambers dan Trudgill, 2007; Ayatrohaedi, 1983; Kridalaksana:2008; Kisyani dan Agustina:2009; Mahsun:1995). Adanya variasi bahasa tersebut merujuk pada adanya perbedaan dalam bahasa yang diperbandingkan. Ayatrohaedi (1983: 3-5) yang mengacu pada pandangan Guiraud (1970) berpendapat bahwa pembeda dialek pada garis besarnya ada lima macam, yakni sebagai berikut: (1) perbedaan fonetis, yaitu perbedaan pada bidang fonologi; (2) perbedaan semantis, yang mencakup (a) sinonimi, yaitu nama yang berbeda untuk linambang yang sama pada beberapa tempat yang berbeda dan (b) homonimi, yaitu nama yang sama untuk hal yang berbeda pada beberapa tempat yang berbeda; (3) perbedaan onomasiologis, yaitu nama yang berbeda berdasarkan satu konsep yang diberikan pada beberapa tempat yang berbeda; (4) perbedaan semasiologis, yaitu nama yang sama untuk beberapa konsep yang berbeda; (5) perbedaan morfologis, yaitu perbedaan dalam bentukan kata.

\section{METODE PENELITIAN}

Penelitian ini berjenis penelitian kualitatif komparatif (Moleong, 2007; Sukidin, 2007). Data dalam penelitian ini adalah bahasa Toraja berdasarkan dua ratus Gloss Swadesh yang dikumpulkan dari informan yang terdapat pada lima lokasi penelitian yaitu Rembon, Makale, Salubarani, Sa'dan, dan Baruppu. Data dari lima lokasi penelitian tersebut dikumpulkan dengan menggunakan teknik wawancara, rekam, dan catat (Mahsun,2007; Djajasudarma, 2006). Data selanjutnya 
dikomparatifkan atau dibandingkan untuk menemukan semasiologis dalam bahasa Toraja.

\section{HASIL DAN PEMBAHASAN}

Untuk menemukan semasiologis dalam bahasa Toraja, dilakukan penelitian di lima kecamatan besar di Tana Toraja dan Toraja Utara. Wilayah Tana Toraja diwakili oleh Rembon, Makale, dan Salubarani. Adapun Toraja Utara diwakili oleh Sa'dan dan Baruppu'. Berikut ini dipaparkan hasil penelitian berdasarkan dua ratus gloss Swadesh

Tabel 1. Data hasil penelitian dua ratus gloss Swadesh di wilayah Tana Toraja

\begin{tabular}{|l|l|l|l|l|l|l|}
\hline No & GLOSS & REMBON & MAKALE & SALUBARANI & SA'DAN & BARUPPU \\
\hline 1 & Abu & Au & Au & Au & Au & Au \\
\hline 2 & Air & Wai & Bui & Wai & Wai & Sakke' $^{\prime}$ \\
\hline 3 & Akar & Waka' & Waka' & Waka' & Waka' & Waka' $^{\prime}$ \\
\hline 4 & Aku & Aku' & Aku' & Aku' & Aku' & Aku' $^{\prime}$ \\
\hline 5 & Alir(Meng) & Lolong & Lolong & Lolong & Lolong & Lolong \\
\hline 6 & Anak & Anak & Anak & Anak & Anak & Anak \\
\hline 7 & Angin & Angin & Angin & Angin & Angin & Angin \\
\hline 8 & Anjing & Asu & Asu & Asu & Asu & Asu \\
\hline 9 & Apa & Apara & Apa & Apa & Apa & Apara \\
\hline 10 & Api & Api & Api & Api & Api & Api \\
\hline 11 & Apung & Unnaang & Naang & Nawang & Unnawang & Nayang \\
\hline 12 & Asap & Rambu & Rambu & Rambu & Rambu & Rambu \\
\hline 13 & Awan & Salebu & Salebu & Salebu & Salebu & Gaun \\
\hline 14 & \multirow{2}{*}{ Bagaimana } & Umbasusi & $\begin{array}{l}\text { Umbanaku } \\
\text { a }\end{array}$ & Umbanakua & Umbasusi & Umbasusi \\
\hline 15 & Baik & Melo & Mellong & Melo & Melo & Melo \\
\hline 16 & Bakar & Tunu & Tunu & Tunu & Tunu & Tunu \\
\hline 17 & Balik & Sule & Sule & Sule & Sule & Sule \\
\hline 18 & Banyak & Buda & Buda & Buda & Buda & Buda \\
\hline 19 & Bapak & Ambe' & Ambe' & Ambe' & Ambe' & Ambe' \\
\hline 20 & Baring & Mamma' & Mamma' & Mamma' & $\begin{array}{l}\text { Mamma'- } \\
\text { mamma' }\end{array}$ & $\begin{array}{l}\text { Mamma'- } \\
\text { mamma' }\end{array}$ \\
\hline 21 & Baru & Manenya & $\begin{array}{l}\text { Mane } \\
\text { mangka }\end{array}$ & Baru & Ba'ru' & Bakaru \\
\hline
\end{tabular}




\begin{tabular}{|c|c|c|c|c|c|c|}
\hline 22 & Basah & $\begin{array}{l}\text { Maranda } \\
\text { ng }\end{array}$ & $\begin{array}{l}\text { Marandan } \\
\mathrm{g}\end{array}$ & Maluo & Marandang & Tamme \\
\hline 23 & Batu & Batu & Batu & Batu & Batu & Batu \\
\hline 24 & Berapa & Pira & Pira & Pira & & Pira \\
\hline 25 & Belah(Mem) & Dipiak & Piak & Piak & Ma'piak & Piak \\
\hline 26 & Benar & Tongan & Tongan & Tongan & Tongan & Tongan \\
\hline 27 & Benih & Banne & Banne & Banne & Banne & Banne \\
\hline 28 & Bengkak & Koyong & Kambang & Kambang & Bangke & Kambang \\
\hline 29 & Berenang & Unnorong & Norong & Innorong & Unnorong & Norong \\
\hline 30 & Berjalan & $\begin{array}{l}\text { Lumingk } \\
\text { a }\end{array}$ & Ma'lingka & Ma'lingka & Ma'lingka & Ma'likka \\
\hline 31 & Berat & Mabanda' & Magasa & Banda' & Magasa & Magasa \\
\hline 32 & Beri & Diben & Benni & Diben & Ben & Benni \\
\hline 33 & Besar & Kapua & Kapua & Kapoa & Kapua & Kapua \\
\hline 34 & Bilamana & Umbasusi & $\begin{array}{l}\text { Umbanaku } \\
\text { a }\end{array}$ & Piran & Piranra & $\begin{array}{l}\text { Umbanaku } \\
\text { a }\end{array}$ \\
\hline 35 & Binatang & Olo'-olo' & Olo'-olo' & Olok-olok & Patuan & Olo'-olo' \\
\hline 36 & Bintang & Bitten & Bintoen & Bintoen & Bintoen & Bettoen \\
\hline 37 & Buah & Buanna & Buah & Buah & Buah & Buanna \\
\hline 38 & Bulan & Bulan & Bulan & Bulan & Bulan & Bulan \\
\hline 39 & Bulu & Bulunna & Bulu & Bulu & Bulu & Bulu \\
\hline 40 & Bunga & Bunga & Bunga & Bunga & Bunga & Bunga \\
\hline 41 & Bunuh & Dipatei & Patei & Patei & Papatean & Patei \\
\hline 42 & Buru(Ber) & Manggula & Mangula' & Rumangan & Muasu & Manggula' \\
\hline 43 & Buruk & $\begin{array}{l}\text { Tangdan } \\
\text { ding }\end{array}$ & $\begin{array}{l}\text { Kadangke } \\
\text { ng }\end{array}$ & Kadake & Kadake & $\begin{array}{l}\text { Kadake/ta } \\
\text { ngdadi }\end{array}$ \\
\hline 44 & Burung & Burung & Burung & Manuk-manuk & $\begin{array}{l}\text { Manuk- } \\
\text { manuk }\end{array}$ & Dassi \\
\hline 45 & Busuk & Bossing & Bosi & Bosi & Bosi & Bosi \\
\hline 46 & Cacing & Kalitting & Kalinting & Kalinting & Kalinting & $\begin{array}{l}\text { Kanjoro/ka } \\
\text { litting }\end{array}$ \\
\hline 47 & Cium & Udung & Udung & Udung & Udung & Udung \\
\hline 48 & Cuci & Basei & Basei & Basei & Basei & Basei \\
\hline 49 & Daging & Duku & Duku' & Juku & Duku' & Duku' \\
\hline 50 & Dan & Sola & Sola & $\mathbf{N a}$ & Sia & $\mathbf{N a}$ \\
\hline 51 & Danau & Rawa- & Danau & Limbong & Danau & Limbong \\
\hline
\end{tabular}




\begin{tabular}{|c|c|c|c|c|c|c|}
\hline & & rawa & & & & \\
\hline 52 & Darah & Rara & Rara & Rara & Rara & Rara \\
\hline 53 & Datang & Sae & Rampo & Sae & Sae & Sae/rate \\
\hline 54 & Daun & Daun & Daun & Daun & Daun & Daun \\
\hline 55 & Debu & Abu & Abu & Abu & Sowok & Sok \\
\hline 56 & Dekat & $\begin{array}{l}\text { Mandapp } \\
\text { i' }\end{array}$ & Mandappi' & Mandappi' & Mandappi' & Mandappi' \\
\hline 57 & Dengan & Sola & Sola & Sola & Sola & Sola \\
\hline 58 & Dengar & Rangngi & Rangngi & Rangi & Rangi & Rangi \\
\hline 59 & $\mathrm{Di}$ & Dio & Yo & Jio & Jo & Jo \\
\hline 60 & Di Dalam & Lan & Lan & Lan & Lan & Lan \\
\hline 61 & Di Mana & Umbanai & Umbanai & Umbanai & Umbani & Umbani \\
\hline 62 & Dingin & Madi'dik & Di'dik & Madi'dik & Masakka' & Madi'dik \\
\hline 63 & Diri(Ber) & Bendan & Bendan & Ke'de' & Ke'de' & Be'dang \\
\hline 64 & Di Sini & Inde'te & Inde'te & Inde'te & Inde'te & Inde'te \\
\hline 65 & Di Situ & Inde'tu & Inde'tu & Inde'tu & Inde'tu & Inde'tu \\
\hline 66 & Dorong & \begin{tabular}{|l|} 
Turrun \\
\end{tabular} & Surrun & Turrun & \begin{tabular}{|l|} 
Surrun \\
\end{tabular} & Surrun \\
\hline 67 & Dua & Da'dua & Da'dua & Da'dua & Da'dua & Da'dua \\
\hline 68 & Duduk & \begin{tabular}{|l|} 
No'ko' \\
\end{tabular} & Ma'dokko' & No'ko' & \begin{tabular}{|l|} 
Unno'ko' \\
\end{tabular} & Ma'dokko \\
\hline 69 & Ekor & Ikko' & Ikko' & Ikko' & Ikko' & Ikko' \\
\hline 70 & Empat & $\mathrm{A}^{\prime} \mathbf{p a}^{\prime}$ & $\mathrm{A}^{\prime} \mathrm{pa}^{\prime}$ & A'pa' & $\mathrm{A}^{\prime} \mathrm{pa}^{\prime}$ & $\mathrm{A}^{\prime} \mathrm{pa}^{\prime}$ \\
\hline 71 & Engkau & Iko & Iko/kamu & Iko/kamu & Kamu & Iko \\
\hline 72 & Gali & Karo & Kumba' & Kali & Manguali & Dikali \\
\hline 73 & Garam & Sia & Sia & Sia & Sia & Sia \\
\hline 74 & Garuk & \begin{tabular}{|l|} 
Kayok \\
\end{tabular} & Kayok & Kajok & Kayo & Kaok \\
\hline 75 & Gemuk & Maloppo & Malompo & Malompo & Maloppok & Maloppo \\
\hline 76 & Gigi & Isi & Isi & Isi & Isi & Isi \\
\hline 77 & Gigit & \begin{tabular}{|l|} 
Kekkei \\
\end{tabular} & Keke' & Kengke & Keke' & Keke' \\
\hline 78 & Gosok & Ruda' & Russui & Sossok & \begin{tabular}{|l|} 
Sossok \\
\end{tabular} & Ridi' \\
\hline 79 & Gunung & Buntu & Buntu & Buntu & \begin{tabular}{|l|} 
Tanete \\
\end{tabular} & Tanite \\
\hline 80 & Hantam & \begin{tabular}{|l|} 
Kambei \\
\end{tabular} & Gesong & Digesong & \begin{tabular}{|l|} 
Kambei \\
\end{tabular} & Pissanni \\
\hline 81 & Hapus & Sapui & Sapui & Dialai & Pa'dei & Pa'dei \\
\hline 82 & Hati & Penaa & Ate & Penaa & Penaa & Penaa \\
\hline 83 & Hidung & Illong & Illong & Illong & Illong & Illong \\
\hline 84 & Hidup & Tuo & Tuo & Tuo & \begin{tabular}{|l|} 
Tuo \\
\end{tabular} & Tuo \\
\hline 85 & Hijau & Maido & Maido & Maido & Maido & Maido \\
\hline 86 & Hisap & Memmok & Sussu & Mok & Surru' & Surru' \\
\hline
\end{tabular}




\begin{tabular}{|c|c|c|c|c|c|c|}
\hline 87 & Hitam & Malotong & Malotong & Lotong & Malotong & Malotong \\
\hline 88 & Hitung & Reken & Reken & Reken & Reken & Reken \\
\hline 89 & Hujan & Uran & Uran & Uran & Uran & Uran \\
\hline 90 & Hutan & Panggala' & Panggala' & Panggala' & Panggala' & Panggala' \\
\hline 91 & $\mathrm{Ia}$ & Io & Io & Io & Io & Io \\
\hline 92 & Ibu & Indo' & Indo' & Indo & Injo' & Indo' \\
\hline 93 & Ikan & Bale & Bale & Bale & Bale & Bale \\
\hline 94 & Ikat & Pori & Pori & Pori & Pori & Pori \\
\hline 95 & Istri & Baine & Baine & Baine & Baine & Baine \\
\hline 96 & Ini & Iate & Inde & Indee & Yate & Inde' $^{\prime}$ \\
\hline 97 & Itu & Iato & Iti & Itu & Iatu & Iti'o \\
\hline 98 & Jahit & Dasi' & Dasi' & Jai' & Dasi' & Dasi' \\
\hline 99 & Jalan & Lalan & Lalan & Lalan & Lalan & Lalan \\
\hline 100 & Jantung & Bauna & Buana & Buana & Bua & Buana \\
\hline 101 & Jatuh & Ronno' & Tobang & Ronno & Meronno' & Melolin \\
\hline 102 & Jauh & Mambela & Mambela & Mambela & Mambela & Mambela \\
\hline 103 & Kabut & $\begin{array}{l}\text { Salebu } \\
\text { melambi }\end{array}$ & Malillin & Sale uran & Gaun & Salebu \\
\hline 104 & Kaki & Ettek & Lentek & Aje & Lette' $^{\prime}$ & Lette' $^{\prime}$ \\
\hline 105 & Kalau & Yake & Susito & Yakenna & Yake & Yake \\
\hline 106 & Kami,Kita & Mintu & Kami & Kami & Kita & Kami \\
\hline 107 & Kamu & Kamu & Kamu & Kamu/iko & Iko/kamu & Iko' \\
\hline 108 & Kanan & Kanan & Kanan & Kanan & Kanan & Kanan \\
\hline 109 & Karena & Yake & Saba' & Saba' & Saba' & Saba'na \\
\hline 110 & Kata(Ber) & Ma'kada & Ma'kada & Ma'kada & Ma'kada & Ma'kada \\
\hline 111 & Kecil & Bitti' & Bitti' & Bitti' & Bitti' & Bittik \\
\hline 112 & Kelahi(Ber) & Sibobo' & Sibobo' & Sibobo' & Siraka' & Siala \\
\hline 113 & Kepala & Ulu & Ulu & Ulu & Ulu & Ulu \\
\hline 114 & Kering & Marekko & Marangke & Marengko & Marekko & Marakke \\
\hline 115 & Kiri & Kairi & Kiri & Kairi & Kairi & Kairi \\
\hline 116 & Kotor & Maruttak & Maruttak & Sarepa & Mariga & Marota' \\
\hline 117 & Kuku & Kanuku & Kanuku & Kanuku & Kanuku & Kanuku \\
\hline 118 & Kulit & Kuli' & Kuli' & Kuli' & Kuli' & Kuli' \\
\hline 119 & Kuning & Mariri & Mariri & Mariri & Mariri & Mariri \\
\hline 120 & Kutu & Kutu & Kutu & Kutu & Kutu & Kutu \\
\hline 121 & Lain & $\begin{array}{l}\text { Sengnga' } \\
\text { na }\end{array}$ & Senga' & Senga' & Senga' & Senga' \\
\hline
\end{tabular}




\begin{tabular}{|c|c|c|c|c|c|c|}
\hline 122 & Langit & Langi' & Langi' & Langi' & Langi' & Langi' \\
\hline 123 & Laut & Tasik & Tasik & Tasik & Tasik & Tasik \\
\hline 124 & Lebar & Babana & Kalua' & Kalua' & Kalua' & Kalua' \\
\hline 125 & Leher & \begin{tabular}{|l} 
Baroko \\
\end{tabular} & Baroko & Baroko & Baroko & Kollong \\
\hline 126 & Lelaki & \begin{tabular}{|l|} 
Muane \\
\end{tabular} & Muane & Muane & \begin{tabular}{|l|} 
Muane \\
\end{tabular} & Muane \\
\hline 127 & Lempar & Ladang & Leba' & Lekko' & Leba' & Leba' \\
\hline 128 & Licin & Malelo' & Lelo' & Lelo' & Le'lok & Malelo' \\
\hline 129 & Lidah & Lila & Lila & Lila & Lila & Lila \\
\hline 130 & Lihat & Tiro & Tiro & Tiro & Tiro & Tiroi \\
\hline 131 & Lima & Lima & Lima & Lima & Lima & Lima \\
\hline 132 & Ludah & Elo' & Elo' & Elo' & Tudu & Elo' \\
\hline 133 & Lurus & Maruru' & Malolo & Maruru' & \begin{tabular}{|l|} 
Malolo \\
\end{tabular} & Malolo \\
\hline 134 & Lutut & Kuttu' & Guntu' & Guntu' & Guntu' & Kuttu' \\
\hline 135 & Main & $\begin{array}{l}\text { Maningng } \\
\text { o }\end{array}$ & Maninggo & Maninggo & Maninggo & Maninggo \\
\hline 136 & Makan & Kumande & Kumande & Kumande & Kumande & Kumande \\
\hline 137 & Malam & Mabongi & Bongi & Bongi & Bongi & Bongi \\
\hline 138 & Mata & Mata & Mata & Mata & Mata & Mata \\
\hline 139 & Matahari & Mataallo & Mataallo & Mataallo & Mataallo & Allo \\
\hline 140 & Mati & Mate & Mate & Mate & Mate & Mate \\
\hline 141 & Merah & Mararang & Mararang & Malea & Mararang & Mararang \\
\hline 142 & Mereka & Kita' & To senga' & Yanasangtu & Yatumati & Ya'i \\
\hline 143 & Minum & Iru' & Mangngiru' & Mangngiru' & Mangngiru' & Mangngiru' \\
\hline 144 & Mulut & Puduk & Puduk & Puduk & \begin{tabular}{|l|} 
Sadang \\
\end{tabular} & Puduk \\
\hline 145 & Muntah & Tilua & Tilua & Tilua & Tilua & Tilua \\
\hline 146 & Nama & Sanga & Sanga & Sanga & Sanga & Sanga \\
\hline 147 & Napas & Penaa & Penaa & Penawa & Penawa & Penaa \\
\hline 148 & Nyanyi & Nani & Menani & Nani & Menani & Menani \\
\hline 149 & Orang & Tau & Tau & Tau & Tau & Tau \\
\hline 150 & Panas & Malassu & Malassu & Malassu & \begin{tabular}{|l|} 
Malassu \\
\end{tabular} & Malassu \\
\hline 151 & Panjang & Kalando & Kalando & Kalando & Kalando & Kalando \\
\hline 152 & Pasir & Kassi' & Kassi' & Kassi' & Kassi' & Karassik \\
\hline 153 & Pegang & Toi & Toi & Toi & Toi & Toi \\
\hline 154 & Pendek & \begin{tabular}{|l|} 
Kondi' \\
\end{tabular} & Kondi' & Kadotti' & Karondi' & Kondi' \\
\hline 155 & Peras & Parra & Parra & Parra & Parra & Parrai \\
\hline 156 & Perempuan & Baine & Baine & Baine & Baine & Baine \\
\hline 157 & Perut & Tambuk & Tambuk & Tambuk & Tambuk & Tambuk \\
\hline
\end{tabular}




\begin{tabular}{|c|c|c|c|c|c|c|}
\hline 158 & Pikir & Tangnga' & Tangnga' & Tangnga' & Tangnga' & Tangnga' \\
\hline 159 & Pohon & Kayu & Kayu & Garonto' kayu & Kayu & Kau \\
\hline 160 & Potong & Le'to & Le'to & Le'to & Polo & Polo \\
\hline 161 & Punggung & Boko' & Palempeng & Palempeng & Sokkong & Paleppeng \\
\hline 162 & Pusar & Posi' & Posi' & Posi' & Posi' & Posi' \\
\hline 163 & Putih & Mabusa & Mabusa & Mabusa & Mabusa & Mabusa \\
\hline 164 & Rambut & Beluak & Beluak & Biluak & Beluak & Buliak \\
\hline 165 & Rumput & Reu & Riu & Reu & Riu & Riu \\
\hline 166 & Satu & Misa' & Misa' & Mesa' & Mesa' & Misa' \\
\hline 167 & Sayap & Pani' & Pani' & Pani' & Pani' & Pani' \\
\hline 168 & Sedikit & Sissi' & Sidi' & Sissi' & Siddo' & Sido' \\
\hline 169 & Siang & Masero & Masiang & Masiang & Masiang & Masiang \\
\hline 170 & Siapa & Minda & Mindanna & Inda & Mennara & Minda \\
\hline 171 & Sempit & Si'pi' & Si'pi' & Sippi' & Si'pi' & Si'pi' \\
\hline 172 & Semua & Mettu' & Mintu & Mintu & Mintu & Mittu' \\
\hline 173 & Suami & Muane & Muane & Muane & Muane & Muane \\
\hline 174 & Sungai & Salu & Salu & Salu & Salu & Salu \\
\hline 175 & Tajam & Mataran & Mataran & Mataran & Mataran & Mataran \\
\hline 176 & Tahu & Tandai & Natandai & Tandai & Tandai & Natandai \\
\hline 177 & Tahun & Taun & Taun & Taun & Taun & Taun \\
\hline 178 & Takut & Matakku' & Mataku' & Mataku' & Magiang & Mataku' \\
\hline 179 & Tali & Ulang & Ulang & Ulang & Ulang & Ulang \\
\hline 180 & Tanah & Padang & Litak & Litak & Losso' & Losso' \\
\hline 181 & Tangan & Lima & Lima & Lima & Lima & Lima \\
\hline 182 & Tarik & Tare' & Tare' & Riu' & Riu' & Nariu' \\
\hline 183 & Tebal & $\begin{array}{l}\text { Makamba } \\
\text { n }\end{array}$ & Makamban & Makamban & Makamban & Maka'ba' \\
\hline 184 & Telinga & Talingnga & Talinga & Talinga & Talinga & Talinga \\
\hline 185 & Telur & Tallo' & Tallo' & Tallo' & Tallo' & Tallo' \\
\hline 186 & Terbang & Mettia' & Mentia' & Mentia' & Mettia' & Mettia' \\
\hline 187 & Tertawa & Metawa & Metaa & Metawa & Meta & Metaa \\
\hline 188 & Tetek & Susu & Susu & Susu & Susu & Susu \\
\hline 189 & Tidak & Tae' & Tae' & Tae' & Tae' & Tae' \\
\hline 190 & Tidur & Mamma' & Mamma' & Mamma' & Mamma' & Mamma' \\
\hline 191 & Tiga & Tallu & Tallu & Tallu & Tallu & Tallu \\
\hline 192 & Tikam & Tobok & Tibok & Gajang & Tobok & Narere' \\
\hline 193 & Tipis & Manipi' & Manipi' & Nipi' & Manipi' & Manippi' \\
\hline
\end{tabular}




\begin{tabular}{|l|l|l|l|l|l|l|}
\hline 194 & Tiup & Pamurru' & Pamurru' & Sue & Pamurru' & Burra \\
\hline 195 & Tongkat & Tekken & Tekken & Tekken & Tekken & Tekken \\
\hline 196 & Tua & Matua & Matua & Tua & Matua & Matua \\
\hline 197 & Tulang & Buku & Buku & Buku & Buku & Buku \\
\hline 198 & Tumpul & Mapa'pa & $\begin{array}{l}\text { Tangnabel } \\
\text { a }\end{array}$ & Pompong & Mapa'pa & $\begin{array}{l}\text { Tangnata } \\
\text { ma }\end{array}$ \\
\hline 199 & Ular & Ula' & Ula' & Ula' & Ula' $^{\prime}$ & Ula' \\
\hline 200 & Usus & Tambuk & Tambuk & Tambuk & Kosso' & Tambuk \\
\hline
\end{tabular}

Berdasarkan penelitian yang telah dilakukan, ditemukan beberapa kata dalam bahasa Toraja yang menunjukkan adanya gejala semasiologis. Gejala tersebut, antara lain dapat dilihat pada kata sia. Kata sia merupakan salah satu kata yang menunjukkan adanya semasiologis dalam bahasa Toraja. Kata atau bentuk sia bermakna garam. Namun selain bermakna garam kata sia juga bermakna atau berkonsep dengan dan dan. Perbedaan konsep tersebut, dapat dilihat pada contoh kalimat berikut ini.

(1) Kurang sia tu pantollo'mu!

/Kurang//garam//itu//masakanmu/

Masakanmu itu kurang garam!

Semasiologis dalam bahasa Toraja juga dapat ditemukan pada kata sola. Sama halnya dengan sia, sola juga merupakan bentuk atau nama yang sama untuk beberapa konsep yang berbeda. Kata sola memiliki memiliki tiga konsep yaitu dan, dengan, dan teman atau kawan. . Perbedaan konsep tersebut, dapat dilihat pada contoh kalimat berikut ini.

(2) Solaku tu!

/Temanku/ /itu/

Itu temanku!!

Gejala nama yang sama untuk beberapa konsep yang berbeda juga ditemukan pada kata tambuk. Kata tambuk dapat bermakna usus. Namun di sisi lain, tambuk juga bermakna perut. Perbedaan kedua kata tersebut dapat dilihat pada kalimat berikut ini.

(3) Masaki tambuk sumpuan tu Bira"!

/Sakit/ /usus/ /buntu/ /Bira'/

Bira' sakit usus buntu 
Semasiologis juga dapat dilihat pada kata penaa. Bentuk kata penaa merupakan salah satu kata yang menunjukkan adanya semasiologis dalam bahasa Toraja. Kata atau bentuk penaa bermakna hati. Namun selain bermakna hati kata penaa juga bermakna atau berkonsep nafas. Perbedaan konsep tersebut, dapat dilihat pada contoh kalimat berikut ini.

(7) Mapa'dik penaangku na sengkei!

/Sakit/ /hati/ /saya//dimarahi/

Hati saya saki dimarahi!

Selain kata-kata di atas, semasiologis dalam bahasa Toraja juga dapat ditemukan pada kata ula'. Sama halnya dengan penaa, ula' juga merupakan bentuk atau nama yang sama untuk beberapa konsep yang berbeda. Kata ula' bermakna kejar, namun di sisi lain, ula' juga bermakna ular. Perbedaan konsep tersebut, dapat dilihat pada contoh kalimat berikut ini.

(8) diula'na'!

/dikejar//saya/

saya dikejar!

Kata baine dalam bahasa Toraja juga menunjukkan adanya semasiologis. Kata baine sama halnya kata-kata yang lain sebelumnya juga menunjukkan dua konsep yang berbeda. Kata baine dapat bermakna istri, namun juga bermakna perempuan. Perbedaan konsep tersebut, dapat dilihat pada contoh kalimat berikut ini.

(9) Den mo bainemu?

\section{/Ada//sudah/ /istrimu/}

Sudah ada istrimu?

Selain kata baine, kata muane juga menunjukkan adanya semasiologis bahasa Toraja. Kata muane, sama halnya kata baine menunjukkan adanya bentuk bahasa yang sama namun memiliki konsep atau makna yang berbeda. Kata muane dapat berarti suami, namun dapat pula bermakna laki-laki.

Den mo muanemu?

/Ada//sudah//suamimu/

Sudah ada suamimu?

Gejala nama yang sama untuk beberapa konsep yang berbeda juga ditemukan pada kata lima. Kata lima dapat bermakna tangan. Namun di 
sisi lain, lima juga bermakna angka lima. Perbedaan kedua kata tersebut dapat dilihat pada kalimat berikut ini.

(11) Allian ki sia limA bungku'. /Belikan/ /kita/ /garam/ /lima/ /bungkus/ Belikan kita garam sebanyak lima bungkus.

\section{SIMPULAN}

Berdasarkan pemaparan data di atas dapat disimpulkan bahwa dalam bahasa Toraja ditemukan adanya semasiologis. Semasiologis merujuk pada makna adanya dua bentuk bahasa yang sama namun memiliki konsep atau makna yang berbeda. Semasiologis dalam bahasa Toraja dapat ditemukan pada kata sia, sola, tambuk, penaa, ula', baine, muane, dan lima. Berdasarkan dua ratus Gloss Swadesh yang digunakan, ditemukan pula adanya onomasiologis dalam bahasa Toraja.

\section{DAFTAR PUSTAKA}

Ayatrohaedi. 1983. Dialektologi: Sebuah Pengantar. Jakarta: Pusat Pembinaan dan Pengembangan Bahasa Departemen Pendidikan dan Kebudayaan.

Chambers, J.K, dan Peter Trudgill. 2007. Dialectology: Second Edition. Cambridge: Cambridge University Press.

Djajasudarma, Fatimah. 2006. Metode Linguistik: Ancangan Metode Penelitian dan Kajian. Bandung: Refika Aditama.

Kisyani, Laksono dan Agusniar dian Saviyri. 2009. Dialekologi.

Surabaya: Unesa Press.

Kridalaksana, Harimurti. 2008. Kamus Linguistik. Jakarta: Gramedia Pustaka Utama.

Mahsun. 1995. Dialektologi Diakronis: Sebuah Pengantar. Yogyakarta:Gajah Mada University Press.

Mahsun. 2006. Metode Penelitian Bahasa: Tahapan Strategi, Metode, dan Tekniknya. Jakarata: Raja Grafindo.

Nadra dan Reniwati. 2009. Dialektologi: Teori dan Metode.Yogyakarta: Elmatera Publishing.

Moleong, Lexy J. 2007. Metodologi Penelitian Kualitatif. Bandung: Penerbit PT Remaja Rosdakarya Offset 